\title{
Metacognitive approaches to the treatment of psychosis: a comparison of four approaches
}

This article was published in the following Dove Press journal:

Psychology Research and Behavior Management

\author{
Paul H Lysaker ${ }^{1,2}$ \\ Emily Gagen ${ }^{3}$ \\ Steffen Moritz ${ }^{4}$ \\ Robert D Schweitzer ${ }^{5}$ \\ 'Department of Psychiatry, \\ Richard L Roudebush VA Medical \\ Center, Indianapolis, IN, USA; \\ 2Department of Psychiatry, Indiana \\ University School of Medicine, \\ Indianapolis, IN, USA; ${ }^{3}$ Department \\ of Psychology and Neuroscience, \\ University of North Carolina at \\ Chapel Hill, Chapel Hill, NC, USA; \\ ${ }^{4}$ Department of Psychiatry and \\ Psychotherapy, University Medical \\ Center Hamburg-Eppendorf, Hamburg, \\ Germany; ${ }^{5}$ School of Psychology and \\ Counselling, Queensland University of \\ Technology, Brisbane, QLD, Australia
}

Correspondence: Paul Lysaker Department of Psychiatry, Richard L Roudebush VA Medical Center, II6A, I48I West I0th Street, Indianapolis, IN 46202, USA

Email plysaker@iupui.edu

\begin{abstract}
In light of increasing interest in metacognition and its role in recovery from psychosis, a range of new treatments focused on addressing metacognitive deficits have emerged. These include Metacognitive Therapy, Metacognitive Training, metacognitive insight and reflection therapy, and metacognitive interpersonal therapy for psychosis. While each of these treatments uses the term metacognitive, each differs in terms of their epistemological underpinnings, their structure, format, presumed mechanisms of action, and primary outcomes. To clarify how these treatments converge and diverge, we first offer a brief history of metacognition as well as its potential role in an individual's response to and recovery from complicated mental health conditions including psychosis. We then review the background, practices, and supporting evidence for each treatment. Finally, we will offer a framework for thinking about how each of these approaches may ultimately complement rather than contradict one another and highlight areas for development. We suggest first that each is concerned with something beyond what people with psychosis think about themselves and their lives. Each of these four approaches is interested in how patients with severe mental illness think about themselves. Each looks at immediate reactions and ideas that frame the meaning of thoughts. Second, each of these approaches is more concerned with why people make dysfunctional decisions and take maladaptive actions rather than what comprised those decisions and actions. Third, despite their differences, each of these treatments is true to the larger construct of metacognition and is focused on person's relationships to their mental experiences, promoting various forms of self-understanding which allow for better selfmanagement. Each can be distinguished from other cognitive and skills-based approaches to the treatment of psychosis in their emphasis on sense-making rather than learning a new specific thing to say, think, or do in a given situation.
\end{abstract}

Keywords: schizophrenia, psychosis, metacognition, rehabilitation, psychotherapy, recovery

\section{Introduction}

The past two decades have seen an increasing interest in understanding the role of the mind as evidenced in psychological states. Evidenced in research is the development of theory around such notions as theory of mind, mentalization, reflective functioning, and metacognition. At the same time, we have witnessed a renewed interest in addressing deficits associated with some of the most debilitating psychological disorders, as seen with the introduction of a range of new treatments focused on addressing metacognitive deficits for patients presenting with psychosis including schizophrenia spectrum disorders. Some of these interventions, such as Metacognitive Training ${ }^{1}$ and 
metacognitive insight and reflection therapy (MERIT), ${ }^{2}$ were developed in response to the challenges posed by psychosis and the deficits associated with psychotic processes including compromised coherence of self-experience. Two others, Metacognitive Therapy ${ }^{3,4}$ and metacognitive interpersonal therapy for psychosis (MIT-P) ${ }^{5,6}$ drew upon alternative epistemologies. As therapies, Metacognitive Therapy and MIT-P were originally applied to other clinical groups and later adapted for psychosis. Each of these therapies differs significantly in terms of their epistemological underpinnings, their structure, format, presumed mechanisms of action, and primary outcomes. As has been noted elsewhere, ${ }^{7}$ this is potentially confusing because each treatment uses the term metacognition; this may obstruct an understanding of how these treatments might complement one another both in terms of clinical utility as well as their contributions to understanding disturbances in human consciousness and behavior.

To add clarity to this picture, the current review will explore the background, practices, and supporting evidence for the four metacognitive therapies currently available for psychosis: Metacognitive Therapy, Metacognitive Training, MERIT, and MIT-P. To provide additional clarity, we will first offer a brief history of metacognition as well as its potential role in an individual's response to and recovery from complicated mental health conditions including psychosis. Finally, we will offer a framework for thinking about how each of these approaches may ultimately complement (rather than rival) one another and highlight areas for development.

\section{A brief history of interest in metacognition}

Ancient through contemporary philosophy is replete with work on the nature of human reflection as an essential human activity. Socrates' famous dictum "Know thyself," found across several of Plato's dialogues, is posited as the means for understanding how to make sense of one's life. Pascal's dictum: "Man is a reed, the weakest of nature, but he is a thinking reed" supports the thought that reflection and our sense of ourselves is what makes us human.

In the field of psychology, $\mathrm{James}^{8}$ was possibly the first to develop a theory of self that included the notion of the "me" and the "I." Within this paradigm, the "I" has the capacity to know itself, that is, a capacity for self-observation, while the "me" refers to the individual as object. This gave rise to the duplex self, such that the total self is comprised of both object and subject. ${ }^{8}$ He also introduced the idea of stream of consciousness, which again is intrinsic to sense of self.
Despite the centrality of notions of self-awareness, self-monitoring, and self-direction within the study of the humanities, one of the first formal efforts in psychology that unified these constructs came when Flavell ${ }^{9}$ formally proposed using the term metacognition to capture aspects of consciousness intimately related to these processes. Flavell's ${ }^{9}$ primary interest in utilizing this term was to address issues facing developmental psychology, including the effects (potentially positive and negative) of learners' awareness of their learning and the cognitive processes that enable learning to progress. He writes that a child's ability to "distinguish... between understanding and not understanding things" could change how they behave in educational settings ${ }^{9}$ (p. 909). As noted by Moritz and Lysaker, ${ }^{7}$ Flavell's ${ }^{9}$ original model of metacognition also extended beyond the educational context and thoughts that are about other thoughts to include forms of self-awareness and their culmination in measurable attitudes and actions.

Within the antipodes, there have been similar developments, with the work of Robert Hobson and Meares and the development of the conversational model. ${ }^{10}$ Meares defines the sense of self in terms of a more or less continuous flow of feelings which constitute mental life, that is, images, thoughts, imaginings, and memories. These experiences are often associated with reverie. ${ }^{10}$ The theoretical implications have been applied to the psychotherapy of patients presenting with borderline states. In contemporary psychoanalytic theory, similar ideas are described in terms of the requirements of "the other" for the emergence of the mind. That is, the mind is never isolated, but emerges in conversation with others. Important extensions of the work of Flavell were made by Nelsonet al., ${ }^{11}$ whose model on object versus metalevel has been incorporated in the metacognitive account by Wells, as well as Koriat, ${ }^{12,13}$ whose emphasis on confidence as a metacognitive process is prominent in the account by Moritz and Lysaker. ${ }^{7}$

Since the original definition of metacognition, psychologists and researchers from related fields have studied metacognition in the context of broader human development including attachment, ${ }^{14}$ various cognitive functions including memory and the experience of certainty, ${ }^{15,16}$ and the experience of following one's own cognitive processes as decisions are made and the confidence associated with this process. ${ }^{1}$ Multiple authors have sought to divide metacognition into discrete activities including those which support planning, monitoring behavior, and evaluating outcomes of behavior, as well as those related to knowledge of oneself, knowledge 
of strategies, and knowledge of when and where certain strategies are likely to work. ${ }^{17-19}$

Focusing on psychopathology, Wells ${ }^{20}$ was among the first to suggest that metacognitive beliefs people have about their cognitions affect how persons respond to distress and psychosocial challenges leading to emotional disorders (ie, anxiety, depression). Wells further distinguished himself as advancing cognitive theory and therapy by differentiating these beliefs about beliefs from other cognitive content and tying adaptive changes in these to enhanced awareness of one's own cognitive processes and self-regulation. In this sense, his concept is essentially a single-person model of metacognition. Also focusing on psychopathology, Semerari et $\mathrm{al}^{21}$ sought to further develop the construct of metacognition in at least two ways. First, in the tradition of Flavell, they were careful to note that metacognitive acts can be distinguished from one another on the basis of whether the acts are focused on self, others, or the use of that knowledge, and disturbance in different forms might result in different forms of psychopathology. In this sense, they extended the model to a two-person model. They additionally proposed metacognition could be conceptualized as a series of modular functions that applied to each of these foci (eg, differentiation of mental states and understanding how mental experiences interact).

Focusing on core symptoms of schizophrenia, Moritz et al, ${ }^{1}$ employed the construct of metacognition to suggest how individuals can become aware of their own cognitive distortions and in particular how they can reduce overconfidence in false judgments and ultimately delusional beliefs. In parallel, Lysaker et $\mathrm{al}^{22,23}$ modified the model and approach developed by Semerari et $\mathrm{al}^{21}$ in order to understand basic psychological mechanisms at play in psychotic disorders. In what was later referred to as the integrated model of metacognition, ${ }^{24}$ they proposed that metacognition could be conceptualized as a spectrum of activities which range from discrete activities (eg, noticing specific mental states) to more synthetic activities (eg, integrating discrete experiences into a complex sense of self and others in a given moment). This model retained the original distinctions made by Semerari et $\mathrm{al},{ }^{21}$ which separated metacognitive acts into ones concerned with the self, others, and the use of that knowledge. It also proposed that within each domain of metacognitive acts or metacognition, different levels could be distinguished on the basis of their level of integration. Further, to be able to perform more complex acts of integration, the more discrete functions have to be operating at a sufficient level, otherwise there would not be material available to integrate. In this sense, metacognition can be conceptualized as divisible into distinct hierarchical levels.

\section{The potential role of metacognitive processes in recovery from serious mental illness}

As metacognition has been thought to be foundational to human adaptation and communication, research has rapidly developed exploring whether deficits or alterations in metacognitive function may help explain the development and maintenance of mental health conditions. The construct of metacognition has frequently been applied to understanding serious mental illnesses including psychotic disorders such as schizophrenia. Before we detail these different approaches, it seems important to discuss some of the reasons for this explosion in interest. First, in the wake of singular and perhaps myopic focus on the biological processes which may underpin these disorders, the field has lacked solid models of the psychological processes which contribute to disorder, which can explain disturbances misattributed to simplistic disturbances in biological processes and which could be the target of treatment. These models are needed in order to develop psychosocial treatments that promote wellness beyond the positive symptom reduction afforded by pharmacological treatments that, regardless of their efficacy, involve agents that have significant negative side effects.

Models in which alterations in metacognitive processes are implicated in serious mental illness are good candidates to fill that void for several reasons. Intuitively, metacognition has a clear place as a moderator in the flow from social and biological disturbances to consciousness and behavior. Phenomena such as symptoms, neurocognitive compromise, and trauma and stigma do not just affect the life of a person directly; they elicit perceptions, interpretations, and responses from the individual that in turn affect if and how these phenomena influence his or her life. ${ }^{25}$ As such, alterations in metacognition are linked to how significant experiences and events unfold and affect persons as well. Indeed, deficits in metacognition would potentially negatively affect the development and course of symptoms as well as an individual's ability to recognize and respond to social adversity and ultimately take charge of one's own recovery.

\section{Four emerging treatments Metacognitive Therapy Background}

Metacognitive Therapy ${ }^{4}$ bases its approach on the notion that disorder (ie, generalized anxiety disorder, depression, etc) is 
caused not by the content of one's thoughts, as is posited by traditional cognitive behavioral therapy, but instead by the way in which one's thought processes are controlled and the style in which this is executed. ${ }^{26}$ The Self-Regulatory Executive Function (S-REF) model of dysfunctional processing provides the basis for this supposition. ${ }^{27}$ According to this model an individual's cognitive functioning is comprised of three levels: automatic processing, voluntary processing that places demands on one's attention, and stored knowledge and beliefs about oneself. The S-REF model provides an explanation of how bottom-up (eg, intrusions) in conjunction with top-down processes (especially metacognitive beliefs) contribute to the choice of coping mechanisms that impact psychological well-being.

\section{Practice}

The thinking style associated with the S-REF is the Cognitive Attentional Syndrome (CAS). ${ }^{26}$ This syndrome is considered a universal feature of emotional disorder and consists of three parts: worry and rumination, threat monitoring, and behaviors like avoidance or thought suppression that serve to impair self-control and/or prevent corrective learning experiences. Especially in his older work, Wells ${ }^{28}$ distinguished between Type I and Type II worrying. While Type II is meta-worry (ie, worry about worry such as "I'm losing out in life because of worrying"), Type 1 relates to worry about noncognitive events such as external situations. ${ }^{28}$ These three features are the areas targeted as part of Metacognitive Therapy; it employs attention training, ${ }^{29}$ detached mindfulness, ${ }^{30}$ and situational attentional refocusing. ${ }^{31}$ The basic principle is that individuals must know the best way to respond to threat and negative thoughts; in other words, reduce the CAS. Techniques from standard cognitive behavioral therapy (CBT) may be used (ie, behavioral experiments, examining the evidence), but these approaches are targeted not at the content of the cognition but instead at the metacognitive beliefs about one's thoughts.

In psychosis, negative thoughts are conceptualized by Hutton et $\mathrm{al}^{32}$ as the trigger for distress rather than psychotic experiences themselves. Dimensions of worry have been shown to be associated with dimensions of delusional ideation, and "meta-worry" is associated with distress related to hallucinatory experiences. ${ }^{33}$ Individuals experiencing auditory hallucinations tend to demonstrate higher levels of dysfunctional metacognitive beliefs, and those with delusional beliefs bear similarities to individuals with panic disorder. ${ }^{34}$ The developers of this treatment suggest that these findings are indicative of an individual's beliefs (ie, worry and subsequent rumination) about their experiences of psychosis being the cause of distress rather than the content of the experiences (ie, delusions, hallucinations) themselves.

Metacognitive beliefs about these experiences may also predispose individuals to hallucinations, such that dysfunctional beliefs can contribute to the misattribution of intrusive thoughts to external sources, thus leading to hallucinations. ${ }^{35,36}$ Metacognitive processes are also hypothesized to be associated with the development and maintenance of paranoia; metacognitive worry has been shown to be correlated with both cognitive and emotional dimensions of delusional beliefs, ${ }^{35}$ and may be a means by which individuals manage interpersonal threat. ${ }^{37}$ Indeed, consistent with the S-REF model, positive beliefs about paranoia have been associated with suspiciousness, and negative beliefs about it are related to persecutory delusions. ${ }^{37}$ Some research has also indicated that dysfunctional metacognitive beliefs are predictive of negative affect, perceptions of recovery, and quality of life in individuals with psychosis, above and beyond frequency and severity of positive symptoms. ${ }^{38,39}$

A recent systematic review of the literature demonstrated an association between the CAS and experiences of psychosis and suggested that the CAS has important implications for distress associated with these. ${ }^{40}$ However, a recent metaanalysis concluded that dysfunctional metacognitive beliefs may be primarily associated with psychological disorder and distress defined broadly, rather than with specific diagnoses. ${ }^{41}$ Another recent literature review and meta-analysis concluded that the model proposed by Morrison et $\mathrm{al}^{36}$ regarding the association between hallucination-proneness and dysfunctional metacognitive beliefs in clinical samples is not strongly supported by the literature. ${ }^{42}$ They suggest that these previously observed relationships are in fact quite heterogeneous, and when accounting for comorbid symptoms, appear to be rather weak. As such, it is still unclear whether the models proposed by Wells and colleagues have specific applications to the development and maintenance of psychosis, or whether they are indicative of a broader set of risk factors for the development of psychological distress and disorder.

\section{Evidence}

Metacognitive Therapy has demonstrated effectiveness in several different disorders, including generalized anxiety disorder, ${ }^{43}$ posttraumatic stress disorder, ${ }^{44-46}$ obsessive compulsive disorder, ${ }^{47}$ and depression. ${ }^{48}$ It has also recently been expanded to a group format for individuals with depression, which demonstrated acceptability and feasibility as well as a reduction in mood and cognitive symptoms associated 
with depression in both an open trial ${ }^{49}$ and a small baselinecontrolled trial. ${ }^{50}$ Most trials are small single-blind studies or case studies; as such, more research is needed to strengthen the conclusions drawn by this research.

The utility of Metacognitive Therapy for individuals with psychosis has been promising but limited thus far. A single case study incorporated elements of Metacognitive Therapy into a short-term CBT intervention and demonstrated a decrease in the experience of positive symptoms. ${ }^{51}$ Another case study utilized attention training after a course of CBT and also noted a decrease in positive symptoms and a shift in beliefs about the power of the hallucinations. ${ }^{52} \mathrm{~A}$ case series of three individuals with schizophrenia who received several sessions of Metacognitive Therapy suggested that there was some clinically significant improvement across several symptom domains, ${ }^{32}$ and an open trial with ten individuals with schizophrenia also demonstrated preliminary evidence that Metacognitive Therapy is feasible and can result in some symptom reduction. ${ }^{3}$

\section{Metacognitive Training}

\section{Background}

Metacognitive Training ${ }^{53}$ is a training program, mainly delivered in a group format (though an individual version has been developed; for ease of exposition we will confine the summary to the group version), aimed at addressing the cognitive biases that underlie delusions through a combination of cognitive remediation, CBT for psychosis, and psychoeducation. Metacognitive Training is predicated on the assumption that these biases represent escalations of normal thinking styles. Individuals with psychosis have less insight into these biases $;{ }^{54}$ impairment may play a role in their perpetuation as well. The primary thinking errors targeted include jumping to conclusions, attributional biases, and overconfidence in errors, all of which have been identified as central to delusional ideas..$^{55,56}$

\section{Practice}

Metacognitive Training aims to "sow seeds of doubt" through corrective experiences. This includes presenting neutral scenarios that gently encourage participants to question the conclusions they draw, which is a nonthreatening way to begin the process of reducing the conviction that often accompanies delusions. The modules of Metacognitive Training include a significant focus on jumping to conclusions and a tendency for overconfidence, as these are seen as the primary bases for turning neutral judgments into delusions. The aim is twofold - these cognitive biases are normalized with the hope of reducing stigma and increasing hope, and psychoeducation about the increased tendency for these biases in individuals with psychosis is provided so as to encourage self-efficacy and decrease certainty in one's judgments. Discussion of the content of the delusions is generally kept to a minimum so as to emphasize the metacognitive nature of the training and decrease the possibility for experiences of shame or embarrassment. ${ }^{7}$

\section{Evidence}

Metacognitive Training has been primarily used in individuals with psychosis on both an inpatient and outpatient basis. ${ }^{1,54}$ Metacognitive Training is well tolerated and well-received by patients and is even perceived as "fun," 56 which has been recently confirmed in a meta-analysis showing that acceptance is high. ${ }^{57}$ Most studies demonstrated small to medium effect sizes in the reduction of positive symptoms at the conclusion of the training, and two studies demonstrate longer-term effects. ${ }^{58,59}$ This has been substantiated by two meta-analyses showing significant effects on delusions. ${ }^{57,60}$ It has demonstrated good results against psychoeducation in a recent-onset psychosis group. ${ }^{61}$ Metacognitive Training has also been modified for use in other disorders including obsessive compulsive disorder, ${ }^{62}$ bipolar disorder, ${ }^{63}$ borderline personality disorder, ${ }^{64}$ and depression, ${ }^{65}$ with improvement across various symptom and functional domains. These modified approaches are a more straightforward hybrid of Metacognitive Training and CBT and aim to provide the same metacognitive experiences to patients as a means to correct inaccurate beliefs.

\section{MERIT}

\section{Background}

MERIT, in contrast to many other therapeutic approaches, was developed in response to emerging research conducted first in the United States, but then replicated internationally. MERIT is based on the assertion that individuals with schizophrenia spectrum disorders experience deficits in the ability to form a complex and integrated sense of self and others. These deficits are predictive, independent of illness severity, with concurrent and prospective functional capacities and can change through psychotherapy. ${ }^{24,66}$ MERIT's procedures were developed through extensive exchanges among many clinicians and international researchers intimately familiar with longer-term psychotherapies for adults with psychosis. These conversations, which took place over the course of a year, sought to identify core processes that go beyond common factors and promote growth in 
metacognitive capacity. Each process, it was agreed, had to be measurable but also integrative in nature, or something that could be implemented by therapists from a range of psychotherapeutic backgrounds. The overarching therapy was thus conceptualized as recovery-oriented rather than as a symptom- or problem-focused approach, with a hypothesized therapeutic action proceeding along the following steps: 1) MERIT promotes greater metacognitive capacity; 2) with greater metacognition capacity, persons have access to a more integrated sense of self and others available in the moment; 3) with access to a more integrated sense of self and others in the moment, patients are better able to evolve a personally meaningful idea about what recovery means to them; and 4) with a more personally meaningful idea about what recovery means to the patient, they will be able to direct their own recovery more fully. Because MERIT is responsive to individual patients' fluctuating levels of metacognitive capacity, it is a therapy for all patients regardless of severity or phase of disorder, provided they can and do consent to treatment. ${ }^{2}$

\section{Practice}

In the MERIT model, the growth in metacognitive capacity is proposed as analogous to what takes places in physical therapy. Patients in MERIT work at their maximal level of metacognitive capacity as they think about themselves, think about others, and think about themselves in relation to others within a session. In MERIT the process of reflection, however, is considered to be joint or something that occurs between persons. MERIT therapists do not direct patients on what to think about but think together with patients about what is occurring in the patient's mind and what is occurring between the therapist and patient. Over time, they become able to perform more complex metacognitive acts just as patients in physical therapy work at their maximal capacity physically and become better able to do the things they used to be able to do.

MERIT consists of eight elements. These are not a set of activities executed in a certain order nor a curriculum that is taught in a certain order. Instead, they reflect processes that promote metacognition within each given session. The elements are interrelated and are intended to be synergistic, but they can occur independently. The eight elements are divided into three classes. The first are the content elements, which focus on content that should be present in a session. These are (element 1) attention to the patient's agenda (ie, wishes and needs in the moment) with the understanding that there may be multiple agendas, which may change throughout ses- sions; (element 2) the patient's experience of the therapist's reactions and thoughts about the patient in the moment; (element 3) narrative episodes or the patient's experience within the flow of unique life events; and (element 4) identification of a psychological challenge the patient is facing in life. The second set of elements comprises the process elements. These require ongoing reflection of processes in the moment and include (element 5) discussion of the therapeutic relationship, within which reflections subsumed in the first four elements are taking place, and (element 6) discussion of the general effects of the session in terms of changes or lack of changes in the patient's mind (eg, different thoughts, feelings, or wishes that emerged or changed) as the session unfolded.

The final two elements are the superordinate elements and offer principles that apply to all the previous elements. The first of the superordinate elements (element 7) requires therapists to enter into a collaborative relationship with the patient, during which the therapist may share what is on his or her mind, and their reflections about patients' thoughts about themselves or others that match and do not exceed patients' metacognitive abilities. In parallel, the final element (element 8) requires therapists to stimulate thinking about and match patients' use of metacognitive knowledge to collaboratively discuss ways in which they respond to psychosocial challenges. Here, there is joint reflection about both the psychosocial challenges the patient is facing but also how they as a unique person are responding to the challenge. As in the previous element, there is joint reflection about responses to these challenges that do not exceed patients' capacities for metacognitive mastery. These last elements are intended to ensure that self-reflectivity, awareness of others, and mastery are stimulated in ways that match patients' metacognitive capacity for each domain and thereby offer the maximal opportunity for growth in metacognitive activity. Operational definitions of adherence for each element and criteria for overall adherence are available. ${ }^{2}$

\section{Evidence}

Research supporting MERIT comes from four sources. First, case reports indicate that therapists can successfully deliver MERIT in routine settings and adapt the therapy to the unique needs of very different patients. ${ }^{67-74}$ Second, the results of two qualitative studies suggest that there are unique benefits of MERIT related to the attainment of agency and a more diverse and rich sense of self. ${ }^{75,76}$ Third, two open trials confirm that the intervention can be delivered and accepted 
by patients under routine conditions in outpatient settings and that it can lead to clinically meaningful change. One open trial formally followed MERIT in a 12 week intervention period, ${ }^{77}$ another fully consistent with the elements of MERIT offered a 9-16 month intervention, ${ }^{78}$ with changes in the later trial being detectable several years following the therapy. ${ }^{79}$ Finally, two small randomized controlled trials have reported that patients with schizophrenia and first episode psychosis with poor awareness of illness will accept the treatment $(68 \%$ and $80 \%$ overall completion rates, respectively) without any adverse events and with significant changes in metacognition and awareness of illness, respectively. ${ }^{80,81}$

\section{MIT-P}

\section{Background}

MIT-P ${ }^{82}$ is an adaptation of MIT. ${ }^{83}$ MIT is a distinct approach to the treatment of personality based on the assumptions that maladaptive interpersonal schemas and metacognitive deficits in personality disorders are a barrier to finding ways to meet one's life goals to successfully navigate the challenges of social life. MIT is based on a structured and manualized set of procedures that guide therapists to engage patients and promote metacognition from the first contact to treatment conclusion. The therapeutic action of MIT follows a series of well-defined steps which begins with the development of a collaborative case formulation, followed by the elicitation of detailed autobiographical episodes, the detection of affects and their links with thoughts and actions, the gathering of more autobiographical memories to paint a clear picture of underlying interpersonal schemas, and the formation of hypotheses about these schemas and the use of that knowledge to plan ways to change those schemas.

Following the development of a shared formulation, MIT focuses on helping patients achieve a critical and reflective distance from maladaptive interpersonal schemas and promote opportunities for the experience of healthy elements of the self within the flow of life outside of sessions as well as behavioral activation. Interpersonal processes are a major focus of MIT, and attention is paid to the prevention and repair of ruptures of therapeutic alliance, meta-communication between the therapist and patient, and guided behavioral homework experiments. MIT has recently gained empirical support in two structured case series ${ }^{84,85}$ and in a pilot randomized controlled trial for a short-term group approach. ${ }^{86}$ The extension of MIT to psychosis was supported by a range of research, some of which is shared with the knowledge base of MERIT including findings that alterations exist in metacognitive functioning ${ }^{87,88}$ and narrative structure ${ }^{89}$ in psychosis and that maladaptive interpersonal schemas can be detected in schizophrenia and linked to functional outcomes. ${ }^{90,91}$

\section{Practice}

MIT-P shares with MIT a focus on the aim of developing a shared formulation of psychological functioning, and carefully follows the same procedures outlined in MIT. In a manner similar to MERIT, it also assumes that many patients with psychotic disorders may initially lack the metacognitive capacity to arrive at a detailed formulation of their own maladaptive interpersonal schemas and be able to think critically about their mental states. It thus works initially, when necessary, to build in a very gradual manner basic levels of metacognitive capacity to understand one's mind, taking into account that this capacity continuously fluctuates over time in psychotic patients. On this basis, as soon as possible, MIT-P therapists elicit narrative episodes in order to form a shared understanding of patients' basic experiences of their lived interpersonal world.

MIT-P further operates under the assumption that positive symptoms may be a barrier to healthy metacognitive function, and that, reciprocally, insufficient metacognitive capacity can contribute to symptoms. As such, MIT-P also includes detailed techniques for addressing symptoms. ${ }^{92}$ These include initially empathic responses to suffering caused by these symptoms, normalizing patients' inner experience, and promoting cognitive and behavioral mastery of suffering and related psychosocial challenges. Once these steps have been achieved, therapists seek to elicit narrative episodes in which a symptom occurs, promote patients' understanding of the relationship between emotional distress and symptoms, and explore how maladaptive interpersonal schemas may trigger the emergence of positive symptoms. Finally, patients are guided to use their new understanding of themselves and others in order to respond to symptoms. For example, they can realize that when they appraise themselves as strong, persecutory views of others as more powerful and malevolent are no longer necessary.

\section{Evidence}

To date, the primary evidence supporting MIT-P includes a series of case studies. ${ }^{82,83,92,93}$ Taken together, this evidence is preliminary but offers a basis for future research into the 
feasibility, tolerability, and efficacy of this treatment among symptomatic patients.

\section{Discussion}

In this paper, we have reviewed rapidly expanding work on metacognition and the ways in which this construct is informing novel interventions for working with people presenting with psychosis. Each of these treatments target metacognition in different ways using differing definitions of the term. These treatments further differ in their format: two were developed from existing treatments for other disorders, and two were developed primarily for persons with psychosis. Thus, the question remains whether these treatments are meaningfully connected to one another or whether they are only arbitrarily associated by different usages of the same key words.

In response, we suggest that our review offers several ways in which these treatments could be considered as meaningfully linked. First, each is concerned with something beyond what people with psychosis think about themselves and their lives. Each of these four approaches is interested in how patients with severe mental illness think about themselves. Metacognitive Therapy looks at immediate reactions that frame the meaning of thoughts and how their cognitive system works ultimately leading to better ways to cope or deal with maladaptive ideas. MIT-P looks at the social schemas that underlie interpretations of psychotic experience. Metacognitive Training looks at how persons process information and the respective awareness of distorted processes, while MERIT is concerned with how persons integrate information to form larger pictures of their lives.

Second, each of these approaches is more concerned with why people make dysfunctional decisions and take maladaptive actions rather than what comprised those decisions and actions. Metacognitive Therapy sees dysfunctional behavior as stemming from assumptions about general classes of ideas, while MIT-P views maladaptive actions as imperfect but understandable reactions to unmet human needs. Metacognitive Training examines identifiable gaps in self-awareness and how persons process information within the flow of life, while MERIT is concerned with enhancing the processes which allow persons to have a coherent and cohesive sense of oneself and others available to them naturally within the flow of life.

Despite their differences, each of these treatments is true to the larger construct of metacognition and is focused on persons' relationships to their mental experiences, promoting various forms of self-understanding which allow for better self-management. Each can be further distinguished from other cognitive- and skills-based approaches to the treatment of psychosis in their emphasis on sense-making rather than learning a new specific thing to say, think, or do in a given situation.

Regarding the differences in how best to define metacognition and thus how outcome is understood, we return to Moritz and Lysaker's ${ }^{7}$ analysis of Flavell's ${ }^{9}$ original use of the term. In particular we, as is suggested in that paper, see each of these approaches as mapping onto a different part of the spectrum of metacognitive activities. At the more discrete corner of the spectrum, we see Metacognitive Therapy as illuminating immediate reactions and reflections as they emerge in the moment across situations, while MIT-P similarly seeks to find interpersonal schemas that exist across situations and also shape one's interpretations and responses to experience. On the other side of the metacognitive spectrum, Metacognitive Training makes plain the intricate processes at play as persons make decisions and respond to the social world, while MERIT offers a glimpse into the complex systems which enable a sense of self and others to be available and to evolve within the flow of life.

In terms of the future, we suggest that this review provides opportunities for important future research questions. This review demonstrates that none of these treatment models on their own adequately accounts for how people know themselves and come to decide how to lead a life that is uniquely their own. More sophisticated and nuanced models are needed that incorporate each piece of the metaphorical elephant grasped by each approach. Also, each approach has much to learn from the others, and the development of future hybrid approaches seems an important avenue to explore.

Finally, there are limitations to this review. We have explored only treatments linked to psychosis; other approaches to metacognition have thus not been considered here due to space limitations. Space also did not allow for a more qualitative exploration of how each treatment is experienced by patients and how each responds to the recovery needs of patients, needs which go beyond symptoms and involve the recapturing of coherent self-experience and agency. More also remains to be explored about just how this treatment really diverges from CBT as well as interfaces with more interpersonal and psychodynamic forms of treatment.

\section{Disclosure}

PL and SM are responsible for developing two of the four models of therapy reviewed in this paper. The authors report no other conflicts of interest in this work.

\section{References}

1. Moritz S, Andreou C, Schneider BC, et al. Sowing the seeds of doubt: a narrative review on metacognitive training in schizophrenia. Clin Psychol Rev. 2014;34(4):358-366. 
2. Lysaker PH, Klion R. Recovery, Meaning-Making, and Severe Mental Illness: A Comprehensive Guide to Metacognitive Reflection and Insight Therapy. New York, NY: Routledge; 2017.

3. Morrison AP, Pyle M, Chapman N, French P, Parker SK, Wells A. Metacognitive therapy in people with a schizophrenia spectrum diagnosis and medication resistant symptoms: a feasibility study. $J$ Behav Ther Exp Psychiatry. 2014;45(2):280-284.

4. Wells A. Meta-cognition and worry: a cognitive model of generalized anxiety disorder. Behav Cogn Psychother. 1995;23(3):301-320.

5. Salvatore G, Procacci M, Popolo R, et al. Adapted metacognitive interpersonal therapy for improving adherence to intersubjective contexts in a person with schizophrenia. Clin Case Stud. 2009;8(6):473-488.

6. Salvatore G, Lysaker PH, Gumley A, Popolo R, Mari J, Dimaggio G. Out of illness experience: metacognition-oriented therapy for promoting self-awareness in individuals with psychosis. Am J Psychother. 2012;66(1):85-106.

7. Moritz S, Lysaker PH. Metacognition - what did James H. Flavell really say and the implications for the conceptualization and design of metacognitive interventions. Schizophrenia Research. In press 2018.

8. James W. The Principles of Psychology. New York, NY: Henry Holt and Company; 1890

9. Flavell JH. Metacognition and cognitive monitoring: a new area of cognitive-developmental inquiry. Am Psychol. 1979;34(10):906-911.

10. Meares R. The conversational model: an outline. Am J Psychother 2004;58(1):51-66.

11. Nelson TO, Stuart RB, Howard C, Crowley M. Metacognition and clinical psychology: a preliminary framework for research and practice. Clin Psychol Psychother. 1999;6(2):73-79.

12. Koriat A. Metacognition research: an interim report. In: Perfect TJ, Schwartz BL, editors. Applied Metacognition. Cambridge, UK: Cambridge University Press; 2002:261-286.

13. Koriat A, Levy-Sadot R. Processes underlying metacognitive judgments: information-based and experience-based monitoring of one's own knowledge In: Chaiken S, Trope Y, editors. Dual Process Theories in Social Psychology. New York: Guilford; 1999:483-502.

14. Main M. Metacognitive knowledge, metacognitive monitoring, and singular (coherent) vs. multiple (incoherent) models of attachment: findings and directions for future research. In: Harris P, StevensonHinde J, Parkes C, editors. Attachment Across the Life Cycle. New York: Routledge; 1991:127-159.

15. Bacon E, Danion JM, Kauffmann-Muller F, Bruant A. Consciousness in schizophrenia: a metacognitive approach to semantic memory. Conscious Cogn. 2001;10(4):473-484

16. Thompson VA, Prowse Turner JA, Pennycook G. Intuition, reason, and metacognition. Cogn Psychol. 2011;63(3):107-140.

17. Dinsmore DL, Alexander PA, Louglin SM. Focusing the conceptual lens on metacognition, self-regulation, and self-regulated learning. Educ Psychol Rev. 2008;20(4):391-409.

18. Schraw G. Promoting general metacognitive awareness. Instr Sci. 1998;26(1-2):113-125.

19. Tarricone P. The Taxonomy of Metacognition. East Sussex, UK: Psychology Press; 2011.

20. Wells A. Emotional Disorders and Metacognition: Innovative Cognitive Therapy. New York, NY: John Wiley and Sons; 2000.

21. Semerari A, Carcione A, Dimaggio G, et al. How to evaluate metacognitive functioning in psychotherapy? The metacognition assessment scale and its applications. Clin Psychol Psychother. 2003;10(4):238-261.

22. Lysaker PH, Carcione A, Dimaggio G, et al. Metacognition amidst narratives of self and illness in schizophrenia: associations with neurocognition, symptoms, insight and quality of life. Acta Psychiatr Scand. 2005;112(1):64-71.

23. Lysaker PH, Vohs JL, Ballard R, et al. Metacognition, self-reflection and recovery in schizophrenia. Future Neurol. 2013;8(1):103-115.

24. Lysaker PH, Hamm JA, Hasson-Ohayon I, Pattison ML, Leonhardt BL. Promoting recovery from severe mental illness: Implications from research on metacognition and metacognitive reflection and insight therapy. World J Psychiatry. 2018;8(1):1-11.
25. Lysaker PH, Lysaker JT. Schizophrenia and the Fate of the Self. Oxford, UK: Oxford University Press; 2008.

26. Wells A. Metacognitive therapy: cognition applied to regulating cognition. Behav Cogn Psychother. 2008;36(6):651-658.

27. Wells A, Matthews G. Modelling cognition in emotional disorder: the S-REF model. Behav Res Ther. 1996;34(11-12):881-888.

28. Wells A. The metacognitive model of GAD: Assessment of meta-worry and relationship with DSM-IV generalized anxiety disorder. Cogn Ther Res. 2005;29(1):107-121.

29. Wells A. Panic disorder in association with relaxation induced anxiety: An attentional training approach to treatment. Behav Ther. 1990;21(3):273-280.

30. Wells A, Matthews G. Self-consciousness and cognitive failures as predictors of coping in stressful episodes. Cogn Emot. 1994;8(3):279-295.

31. Wells A, Papageorgiou C. Social phobia: effects of external attention on anxiety, negative beliefs, and perspective taking. Behav Ther. 1998;29(3):357-370.

32. Hutton P, Morrison AP, Wardle M, Wells A. Metacognitive therapy in treatment-resistant psychosis: a multiple-baseline study. Behav Cogn Psychother. 2014;42(2):166-185.

33. Morrison AP, Wells A. Relationships between worry, psychotic experiences and emotional distress in patients with schizophrenia spectrum diagnoses and comparisons with anxious and non-patient groups. Behav Res Ther. 2007;45(7):1593-1600.

34. Morrison AP, Wells A. A comparison of metacognitions in patients with hallucinations, delusions, panic disorder, and non-patient controls. Behav Res Ther. 2003;41(2):251-256.

35. Morrison AP, Wells A, Nothard S. Cognitive factors in predisposition to auditory and visual hallucinations. Br J Clin Psychol. 2000;39(1):67-78.

36. Morrison AP, Haddock G, Tarrier N. Intrusive thoughts and auditory hallucinations: a cognitive approach. Behav Cogn Psychother. 1995;23(3):265-280.

37. Morrison AP, Gumley AI, Ashcroft K, et al. Metacognition and persecutory delusions: tests of a metacognitive model in a clinical population and comparisons with non-patients. Br J Clin Psychol. 2011;50(3):223-233.

38. Sellers R, Gaw da $\measuredangle$, Wells A, Morrison AP. The role of unhelpful metacognitive beliefs in psychosis: relationships with positive symptoms and negative affect. Psychiatry Res. 2016;246:401-406.

39. Sellers R, Wells A, Parker A, Morrison AP. Do people with psychosis engage in unhelpful metacognitive coping strategies? A test of the validity of the Cognitive Attentional Syndrome (CAS) in a clinical sample. Psychiatry Res. 2018;259:243-250.

40. Sellers R, Wells A, Morrison AP. Are experiences of psychosis associated with unhelpful metacognitive coping strategies? A systematic review of the evidence. Clin Psychol Psychother. 2018;25(1):31-49.

41. Sellers R, Varese F, Wells A, Morrison AP. A meta-analysis of metacognitive beliefs as implicated in the self-regulatory executive function model in clinical psychosis. Schizophr Res. 2017;179:75-84.

42. Varese F, Bentall RP. The metacognitive beliefs account of hallucinatory experiences: a literature review and meta-analysis. Clin Psychol Rev. 2011;31(5):850-864.

43. Wells A, King P. Metacognitive therapy for generalized anxiety disorder: An open trial. J Behav Ther Exp Psychiatry. 2006;37(3):206-212.

44. Wells A, Colbear JS. Treating posttraumatic stress disorder with metacognitive therapy: a preliminary controlled trial. J Clin Psychol. 2012;68(4):373-381.

45. Wells A, Sembi S. Metacognitive therapy for PTSD: A preliminary investigation of a new brief treatment. J Behav Ther Exp Psychiatry. 2004;35(4):307-318.

46. Wells A, Walton D, Lovell K, Proctor D. Metacognitive therapy versus prolonged exposure in adults with chronic post-traumatic stress disorder: a parallel randomized controlled trial. Cogn Ther Res. 2015;39(1):70-80.

47. Fisher PL, Wells A. Metacognitive therapy for obsessive-compulsive disorder: a case series. J Behav Ther Exp Psychiatry. 2008;39(2):117-132. 
48. Wells A, Fisher P, Myers S, Wheatley J, Patel T, Brewin CR. Metacognitive therapy in recurrent and persistent depression: a multiple-baseline study of a new treatment. Cogn Ther Res. 2009;33(3):291-300.

49. Dammen T, Papageorgiou C, Wells A. An open trial of group metacognitive therapy for depression in Norway. Nord $J$ Psychiatry. 2015;69(2):126-131.

50. Papageorgiou C, Wells A. Group metacognitive therapy for severe antidepressant and CBT resistant depression: a baseline-controlled trial. Cogn Ther Res. 2015;39(1):14-22.

51. Hutton P, Morrison AP, Taylor H. Brief cognitive behavioural therapy for hallucinations: can it help people who decide not to take antipsychotic medication? A case report. Behav Cogn Psychother. 2012;40(1):111-116.

52. Valmaggia LR, Bouman TK, Schuurman L. Attention training with auditory hallucinations: a case study. Cogn Behav Pract. 2007;14(2):127-133.

53. Moritz S, Veckenstedt R, Bohn F, Köther U, Woodward TS. Metacognitive training in schizophrenia. Theoretical rationale and administration. In: Roberts DL, Penn DL, editors. Social Cognition in Schizophrenia. From Evidence to Treatment. New York: Oxford University Press; 2013:358-383.

54. Moritz S, Pfuhl G, Lüdtke T, Menon M, Balzan RP, Andreou C. A two-stage cognitive theory of the positive symptoms of psychosis: highlighting the role of lowered decision thresholds. J Behav Ther Exp Psychiatry. 2017;56:12-20.

55. Garety PA, Freeman D. The past and future of delusions research: from the inexplicable to the treatable. Br J Psychiatry. 2013;203(5):327-333.

56. Moritz S, Woodward TS. Metacognitive training in schizophrenia: from basic research to knowledge translation and intervention. Curr Opin Psychiatry. 2007;20(6):619-625.

57. Eichner C, Berna F. Acceptance and efficacy of metacognitive training (MCT) on positive symptoms and delusions in patients with schizophrenia: A meta-analysis taking into account important moderators. Schizophr Bull. 2016;42(4):952-962.

58. Favrod J, Maire A, Bardy S, Pernier S, Bonsack C. Improving insight into delusions: A pilot study of metacognitive training for patients with schizophrenia. J Adv Nurs. 2011;67(2):401-407.

59. Moritz S, Veckenstedt R, Bohn F, et al. Complementary group metacognitive training (MCT) reduces delusional ideation in schizophrenia. Schizophr Res. 2013;151(1-3):61-69.

60. Liu YC, Tang CC, Hung TT, Tsai PC, Lin MF. The efficacy of metacognitive training for delusions in patients with schizophrenia: a meta-analysis of randomized controlled trials informs evidence-based practice. Worldviews Evid Based Nurs. 2018;15(2):130-139.

61. Ochoa S, López-Carrilero R, Barrigón ML, et al. Randomized control trial to assess the efficacy of metacognitive training compared with a psycho-educational group in people with a recent-onset psychosis. Psychol Med. 2017;47(9):1573-1584.

62. Moritz S, Jelinek L, Hauschildt M, Naber D. How to treat the untreated: Effectiveness of a self-help metacognitive training program (myMCT) for obsessive-compulsive disorder. Dialogues Clin Neurosci. 2010;12(2):209-220.

63. Haffner P, Quinlivan E, Fiebig J, et al. Improving functional outcome in bipolar disorder: a pilot study on metacognitive training. Clin Psychol Psychother. 2018;25(1):50-58.

64. Schilling L, Moritz S, Köther U, Nagel M. Preliminary results on acceptance, feasibility, and subjective efficacy of the add-on group intervention metacognitive training for borderline patients. $J \operatorname{Cogn}$ Psychother. 2015;29(2):153-164.

65. Jelinek L, Hauschildt M, Wittekind CE, Schneider BC, Kriston L, Moritz S. Efficacy of metacognitive training for depression: a randomized controlled trial. Psychother Psychosom. 2016;85(4):231-234.

66. Lysaker PH, Buck KD, Ringer J. The recovery of metacognitive capacity in schizophrenia across 32 months of individual psychotherapy: a case study. Psychother Res. 2007;17(6):713-720.

67. Arnon-Ribenfeld N, Bloom R, Atzil-Sloman D, Peri T, de Jong S, Hasson-Ohayon, I. Metacognitive Reflection and Insight Therapy (MERIT) among people with schizophrenia: Lessons from two case studies. Am J Psychother. In press 2018.
68. Hamm JA, Firmin RL. Disorganization and individual psychotherapy for schizophrenia: a case report of metacognitive reflection and insight therapy. J Contemp Psychother. 2016;46(4):227-234.

69. Hasson-Ohayon I, Kravetz S, Lysaker PH. The special challenges of psychotherapy with persons with psychosis: intersubjective metacognitive model of agreement and shared meaning. Clin Psychol Psychother. 2017;24(2):428-440.

70. Hillis JD, Leonhardt BL, Vohs JL, et al. Metacognitive reflective and insight therapy for people in early phase of a schizophrenia spectrum disorder. J Clin Psychol. 2015;71(2):125-135.

71. James A, Leonhardt BL, Buck KD. Metacognitive reflection and insight therapy for schizophrenia: a case study of an individual with a co-occurring substance use disorder. Am J Psychother. In press.

72. Leonhardt BL, Benson K, George S, Buck KD, Shaieb R, Vohs JL. Targeting insight in first episode psychosis: a case study of metacognitive reflection insight therapy (MERIT). J Contemp Psychother. 2016;46(4):207-216.

73. Leonhardt BL, Ratliff K, Buck KD. Recovery in first episode psychosis: a case study of metacognitive reflection and insight therapy (MERIT). Am J Psychother. In press.

74. Van Donkersgoed RJ, De Jong S, Pijnenborg GH. Metacognitive reflection and insight therapy (MERIT) with a patient with persistent negative symptoms. J Contemp Psychother. 2016;46(4):245-253.

75. de Jong S, Hasson-Ohayon I, van Donkersgoed R, Aleman A, Pijnenborg GHM. A qualitative evaluation of the effects of metacognitive reflection and insight therapy: "Living more consciously." Submitted.

76. Lysaker PH, Kukla M, Belanger E, et al. Individual psychotherapy and changes in self-experience in schizophrenia: a qualitative comparison of patients in metacognitively focused and supportive psychotherapy. Psychiatry. 2015;78(4):305-316.

77. de Jong S, Donkersgoed RJM, Aleman A, et al. Practical implications of metacognitive oriented psychotherapy in psychosis: findings from a pilot study. J Nerv Ment Dis. 2016;204(9):713-716.

78. Bargenquast R, Schweitzer RD. Enhancing sense of recovery and selfreflectivity in people with schizophrenia: a pilot study of metacognitive narrative psychotherapy. Psychol Psychother. 2014;87(3):338-356.

79. Schweitzer RD, Greben M, Barenquast R. Long-term outcomes of metacognitive narrative psychotherapy for people diagnosed with schizophrenia. Psychol Psychother. 2017;90(4):668-685.

80. de Jong S, van Donkersgoed RJM, Timmerman ME, et al. Metacognitive reflection and insight therapy (MERIT) for patients with schizophrenia. Psychol Med. 2018:1-11

81. Vohs JL, Leonhardt BL, James AV, et al. Metacognitive reflection and insight therapy for early psychosis: a preliminary study of a novel integrative psychotherapy. Schizophr Res. 2018;195:428-433.

82. Salvatore G, Procacci M, Popolo R, et al. Adapted metacognitive interpersonal therapy for improving adherence to intersubjective contexts in a person with schizophrenia. Clin Case Stud. 2009;8(6):473-488.

83. Dimaggio G, Montano A, Popolo R, Salvatore G. Methacognitive Interpersonal Therapy for Personality Disorders: A Treatment Manual. New York, NY: Routledge; 2015.

84. Dimaggio G, Salvatore G, MacBeth A, Ottavi P, Buonocore L, Popolo R. Metacognitive interpersonal therapy for personality disorders: a case study series. J Contemp Psychother. 2017;47(1):11-21.

85. Gordon-King K, Schweitzer RD, Dimaggio G. Metacognitive interpersonal therapy for personality disorders featuring emotional inhibition: a multiple baseline case series. J Nerv Ment Dis. 2018;206(4): 263-269.

86. Popolo R, MacBeth A, Canfora F, et al. Metacognitive interpersonal therapy in group (MIT-G) for young adults with personality disorders. A pilot randomized controlled trial. Psychol Psychother. Epub 2018 Apr 6.

87. MacBeth A, Gumley A, Schwannauer M, Carcione A, McLeod HJ, Dimaggio G. Metacognition in first episode psychosis: item level analysis of associations with symptoms and engagement. Clin Psychol Psychother. 2016;23(4):329-339.

88. Mitchell LJ, Gumley A, Reilly ES, et al. Metacognition in forensic patients with schizophrenia and a past history of interpersonal violence: an exploratory study. Psychosis. 2012;4(1):42-51. 
89. Lysaker PH, Glynn SM, Wilkness SM, Silverstein SM. Psychotherapy and recovery from schizophrenia: a review of potential application and need for future study. Psychol Serv. 2010;7(2):75-91.

90. Bortolon C, Capdevielle D, Boulenger JP, Gely-Nargeot MC, Raffard S. Early maladaptive schemas predict positive symptomatology in schizophrenia: a cross-sectional study. Psychiatry Res. 2013;209(3):361-366.

91. Johansen R, Melle I, Iversen VC, Hestad K. Personality traits, interpersonal problems and therapeutic alliance in early schizophrenia spectrum disorders. Compr Psychiatry. 2013;54(8):1169-1176.
92. Salvatore G, Ottavi P, Popolo R, Dimaggio G. Metacognitive interpersonal therapy for treating auditory verbal hallucinations in first-onset schizophrenia. J Contemp Psychother. 2016;46(4):235-243.

93. Salvatore G, Buonocore L, Ottavi P, Popolo R, Dimaggio DG. Interpersonal therapy for treating persecutory delusions in schizophrenia. Am J Psychother. In press.
Psychology Research and Behavior Management

\section{Publish your work in this journal}

Psychology Research and Behavior Management is an international, peerreviewed, open access journal focusing on the science of psychology and its application in behavior management to develop improved outcomes in the clinical, educational, sports and business arenas. Specific topics covered in the journal include: Neuroscience, memory and decision making; Behavio
Submit your manuscript here: https://www.dovepress.com/psychology-research-and-behavior-management-journal

\section{Dovepress}

modification and management; Clinical applications; Business and sports performance management; Social and developmental studies; Animal studies. The manuscript management system is completely online and includes a very quick and fair peer-review system, which is all easy to use. Visit http://www. dovepress.com/testimonials.php to read real quotes from published authors. 